Title: Cognitive decline and distinction: a new line of fracture in later life?

Sébastien Libert, Division of Psychiatry, University College London. Maple House, 149 Tottenham Court Road, London W1T 7NF, UK. E-mail: s.libert@ucl.ac.uk

Georgina Charlesworth, Research Department of Clinical, Educational and Health Psychology,

University College London. 1-19 Torrington Place, London WC1E 7HB, UK. E-mail:

g.charlesworth@ucl.ac.uk

Paul Higgs, Division of Psychiatry, University College London. Maple House, 149 Tottenham Court Road, LondonWIT 7NF, UK. E-mail: p.higgs@ucl.ac.uk

Acknowledgments: The research presented in this article was carried out as part of the Marie Skłodowska-Curie Innovative Training Network (ITN) action, H2020-MSCA-ITN-2015, under grant agreement number 676265.

Statement of Ethical Approval: This article is based on a review of the literature and discourse analysis of publicly available material. Ethical approval was therefore not required. 


\title{
Title: Cognitive decline and distinction: a new line of fracture in later life?
}

\begin{abstract}
Cognitive decline and dementia have become major concerns for many individuals reaching later life within contemporary Western societies. This fear of decline is central to the social divide between the third age embodying ideals of maintained health, activity and lifestyle choices, and the fourth age, a social imaginary encompassing the irreversible decline associated with ageing. In this article, we explore how brain training technologies have become successful by relying on tensions between the third and fourth age. We review current debates on the concepts contained in brain training and examine the emphasis on the moral virtue of 'training the brain' in later life as an extension of fitness and health management. We underline the limited consideration given to social positioning within old age itself in the literature. We further argue that using brain training devices can support a distancing from intimations of dementia; a condition associated with an 'ageing without agency'. Drawing on Bourdieu, we use the concept of distinction to describe this process of social positioning. We discuss the impact that such 'technologies of distinction' can have on people with dementia by 'othering' them. We conclude that the issue of distinction within later life, particularly within the field of cognitive decline, is an important aspect of the current culture of active cognitive ageing.
\end{abstract}

Key-words: Brain training, dementia, fourth age, technologies of distinction, active cognitive ageing 


\section{Introduction}

The context of the world-wide increases in the prevalence of dementia among the older population is an established fact to most researchers in gerontology. When combined with frailty, cognitive decline has been seen to represent an important dimension of a 'feared' old age which has been described as a 'fourth age' by a number of commentators (Baltes and Smith 2003; Gilleard and Higgs 2014; Williams, Higgs and Katz 2012). Sarah Harper, gerontologist and former director of the Royal Institution has gone so far as to claim that it is only this period of enfeeblement and decline that should be termed old age: "Old age should be the fourth age. Everything else should be active adulthood" (Brown 2017). Whether this is a useful demarcation or not, it does draw attention to some of the tensions operating between putative third and fourth ages. At a simple level it can be seen as the difference between agency and dependency or between first person and third person accounts of old age. Moreover, while there has been considerable debate about the usefulness of the terms third age and fourth age (Calasanti and King 2011; Hazan 2011; Lloyd et al. 2014), one aspect that has not received as much attention is the notion of individuals engaging with strategies of differentiation within old age itself between third age and fourth age. Some work has been undertaken examining how participation in physical activity at older ages involves a degree of 'othering' of those who take a less active approach to exercise in later life (see for example Allain and Marshall 2017; Phoenix and Smith 2011), but we would argue that this process goes much further than just physical health. In the realm of cognitive health in later life there has been a belief emanating from Medicine that different forms of activity might be crucial in protecting against dementia (Fratiglioni, Paillard-Borg and Winblad, 2004). A recent publication from the Lancet Commission has expanded on the importance of activity by stating that exercise in combination with interventions for other risk factors 'might have the potential to delay or prevent a third of dementia cases' (Livingston et al. 2017:2673). The promotion of these activities as part of both 
governmental and cultural discourses has become a notable feature of contemporary ageing in the UK (Public Health England 2018; Darzi 2014).

As with exercise many aspects of health promotion have the potential to generate implicit social demarcations (Merrild et al. 2017). This we would extend to the realm of ageing and the promotion of what is presented as reducing the risk of dementia. Utilising the idea of 'distinction' developed by Pierre Bourdieu as a way of understanding the processes of cultural reproduction of social class and expanded by others to encompass issues of culture, gender and style, we argue that distinction also plays a role in older people's engagement with 'neurocultural' technologies of the self (Williams, Higgs and Katz 2012). These include both the desire to maintain existing cognitive capacity as well as the wish to prevent cognitive decline. In part this is similar to other accounts of the 'will to health' that feature in accounts of contemporary ageing (Higgs et al. 2009), however this new set of practices goes much further by playing a role in demarcating the boundaries of the third and fourth ages themselves. Correspondingly, in this paper we outline how the new field of 'brain training' has come into existence within the contemporary cultures of ageing. Indeed, we show how one of its key features is the promotion of the idea that it is possible to extend neuro-plasticity not only to enhance the health and wellbeing of older people but also as a means to keep threats of cognitive decline at bay. We then extend the concept of distinction to account for the interest in brain training and show how a concern for differentiation plays an important role in the ever more complex world of contemporary later life. This complexity comes from new environments created by psycho-pharmaceutical interventions, consumer-orientated technologies of the self and the anti-ageing techniques that older people have to negotiate. We conclude that an important aspect of understanding the reconfiguration of ageing in the $21 \mathrm{st}$ century is not only an awareness of the role of the fourth age, but also of the way that it relates to the imperative of agency that marks out participation in the third age. 


\section{The success of brain training and its relation to the divide between the third and fourth}

ages

Before moving on to the concept of distinction per se, we need to provide some contextualisation of the term brain training and its development. In particular we need to identify how it relates to dementia and the cognitive decline often associated with later life. But what is brain training? This is a complex question to answer. Indeed, as Simons et al. (2016:105) point out it refers to two distinct sectors of activity; one is an area of scientific investigation and the other is a commercial endeavour operating within the health and lifestyle markets. Brain training as a scientific endeavour mainly refers to its role as cognitive training and can be included as part of research investigating non-pharmaceutical interventions seeking to evaluate "how training on one or more cognitive tasks generalizes, or "transfers," to performance on other cognitive tasks and to daily life' (ibid.). Brain training usually takes the shape of a software programme available on various electronic devices and usually consists of a set of exercises that the user will undertake on a regular basis, most often multiple times a week or even on a daily basis. Each single exercise aims at training a specific area of the brain as it is defined by researchers in the field of psychology and/or the neurosciences, as well as by the developers of these programmes (One programme Fit brains for instance used the categories: 'speed', 'language', 'logic', 'focus'). Following the model of a fitness programme, the user will initially position himself/herself through a test providing metrics for each of these areas and be placed on a Gaussian curve displaying the scores of other users of the same application. The programme will then establish a series of targets that the user will be expected to reach; alternatively the user will set their own target through comparison with the metrics of the social network of users that are connected to the same application. As such brain training does not focus on the acquisition of skills through learning but is rather concerned with the transferability of skills in order to train the brain to maintain function and avoid decline. Since 
2000 , there has been a remarkable increase in the number of attempts to evaluate brain training technologies in order to assess their utility in preventing, stopping, and even curing the problems associated with cognitive decline and dementia in later life (Simons et al. 2016). These evaluations have even crossed over into popular culture of BBC TV. In 2009, the show 'Bang goes the theory' invited viewers to participate in an evaluation of brain training (Devlin 2009). The programme attracted 11,430 participants who followed a 6-weeks programme of study the results of which formed the basis of an article published in Nature in June 2010. In this article, Owen et al. (2010:775) concluded that 'although improvements were observed in every one of the cognitive tasks that were trained, no evidence was found for transfer effects to untrained tasks, even when those tasks were cognitively closely related'. Thus while more recent research suggests that there is some positive impact on reasoning skills among healthy older adults (Corbett et al. 2015), there has been no consensus on brain training's capacity to delay or prevent the onset of Alzheimer's disease and other forms of dementia (Bahar-Fuchs, Clare and Woods 2013:12). Large-scale research is still ongoing (e.g. The PROTECT Study in the UK).

However, and possibly paradoxically, the commercialisation of brain training has seen considerable growth. Again Simons et al. (2016:106) give us some estimated numbers about the extent of the phenomenon extracted from a market research conducted by a company with the name 'SharpBrains' (2013), who describe themselves as an 'independent market research firm tracking health and performance application of brain science'. Using this source Simons et al. (2016:106) concluded that the 'digital-brain-health market' has grown from sales of $\$ 210$ million in 2005 to $\$ 1.3$ billion in 2013 . They also point to the significant fact that it is estimated that 50 per cent of the end-users are aged 50 or over. Thought the only sources of information about this market come from the sector itself, it still suggests that the brain training market constitutes a significant, and at the present time growing, commercial sector aimed at the older 
population. The popularity of such products may coincide, if we follow George and Whitehouse (2011:590) with a particular moment in the history of dementia treatment in which 20 pharmaceutical trials targeting Alzheimer's disease have already failed. George and Whitehouse see in it a 'therapeutic void' which has probably nourished the market for digital technologies connected to dementia prevention (2011:590). Insofar as it does this, it meets all the characteristics of a political economy of hope - a term developed by Marie-Jo DelVecchio Good et al. (1990) to describe the culture of hope that surrounds the promotion of high-tech treatments in oncology in the United States and around the world. Significantly she also writes about an: 'enthusiasm for medicine's possibilities [that] arises not necessarily from material products with therapeutic efficacy but through the production of ideas with potential but asyet-unproven therapeutic efficacy' (2010:274). This can be equally applied to the case of brain training whose interest in regard to dementia remains to be proven. Exploring the interconnections between health technology and commercial concerns, Nikolas Rose and Carlos Novas have also used the term 'political economy of hope' to describe 'the hope for the innovation that will treat or stimulate the circuits of investment and the creation of biovalue' (2005:442). In our case specifically, we see that the brain training endeavour appears to be a project that generates a high degree of hopeful futures, an effervescent field of research which appears to be a powerful magnet for monetary flows in the private sector. As such, many brain training companies enter the market on the basis of the hopeful futures projected by contemporary neurosciences today (Williams, Higgs and Katz 2012:66). This does not mean that there has not been criticism of these claims. Ethical issues of multiple kinds have emerged relating to this translation from scientific theory to marketable commodity. One company, Lumosity, has been the subject of controversy centring on the need to scientifically validate such technologies before bringing them to the market. ${ }^{i}$ These concerns aside, our focus in this paper is located at another level; the extent to which these hopeful imaginaries, based as they 
are on the active rejection of the intractability of cognitive decline and dementia, can translate into social and individual practices of prevention. The promotion of such hopeful imaginaries among the public therefore demonstrates the importance of this discursive level contained in such technologies.

Work by other researchers has delineated this task. These researchers have examined the marketing campaigns of providers (e.g. George and Whitehouse 2011, Katz and Marshall 2018) and have argued that they are 'socio-cultural objects deeply imbued with the values and ideologies of our age' (George and Whitehouse 2011:590). Consequently these messages draw upon the current social climate around dementia and point out a threat and a promise. For instance, American company Dakim states the following: 'As a result of unprecedented media coverage over the past few years, residents, prospects, and their families are acutely aware of both sides of the brain health issue - the threat of Alzheimer's, and the evidence that brain fitness activities can improve cognitive function and protect the brain from long-term decline [Italic in bold in the original text]'. In this description, the company Dakim directly presents individual action as the way to overcome the threat of Alzheimer's disease. These brain fitness exercises are the brain training products promoted by the same company. Behind them lies the idea of 'neuroplasticity' (Simons et al. 2016:105; Millington 2012:434; Rose and Abi-Rached 2013:48). Neuroplasticity has become a key concept in the development and extension of the neurosciences in recent decades as overarching explanation of mental processes in what have become seen as the neuro-disciplines. Rose and Abi-Rached posit that by the close of the twentieth century, the brain had come to be envisaged as mutable across the whole of life, open to environmental influences, damaged by insults, and nourished and even reshaped by stimulation - in a word plastic" (2013:48). Within the neuro-disciplines, as Rose and AbiRached argue (2013), the brain is no longer viewed as a static object anymore in the sense that decline would be an irreversible process, rather it is a brain that appears to be malleable. As a 
consequence, with the transition to the neuroplastic, the brain becomes receptive to the influence of external human action, and individual agency. In such an understanding, degenerative brain disorders are not perceived as irreversible anymore, and adequate actions can help to compensate the decline through different forms of synaptogenesis and neurogenesis for instance (Pitts-Taylor 2010:636). The cognitive health of the brain in relation to cognitive decline has therefore escaped a form of biological determinism and is an arena where appropriate practices, as well as lifestyle choices can be directed to achieve particular outcomes. Whether or not this is an overtly optimistic reading of potentiality is open to debate, however it does open up an entire field of potential agency in regard to an individual's own brain health, particularly in regard to cognitive decline associated with old age. As such it connects with another idea associated with the work of Nikolas Rose; that of the biological citizen (Rose and Novas 2005). This form of citizenship related to Foucault's notion of governmentality, sees the individual as inserted inside a broader political economy where they are expected to manage responsibly their health through rational calculus. Biological citizenship, translated into the issues surrounding later life (particularly those of health and cognitive decline), can be said to define the parameters of what it is to age 'successfully' or indeed more resonant today to age 'unsuccessfully'.

This is made explicit in the work of Millington (2012:438) who establishes the connection between biological citizenship and the ideal of active ageing which he sees as existing inside brain training technologies. Millington describes how companies operating in the field of brain training 'trade on ageing-related anxieties and exacerbate the pressures on older persons to demonstrate an obvious “will to health" through ongoing consumerism' (2012:430). As Millington points out, under such regimes the older adult comes to be conceptualized as an 'atrisk' (consumer-) citizen who is empowered and capable of sustaining his or her identity into later life (2012:442). Through mentioning the notion of the 'will to health', he points out the 
fact that marketing campaigns attempt to input a social value into consuming brain training products (Ibid.). These marketing campaigns therefore imply that it is a 'good thing' to show to others that we attempt to stay cognitively fit. However, as we will show later, these marketing campaigns, and the values that brain training technologies and associated discourses convey come to articulate a different understanding of the ageing process defined by its "active exclusion of 'old age' and 'agedness"” (Gilleard and Higgs 2010:122). In this way we will argue that an important process of 'othering' occurs within the social relations of later life. This 'othering' process pushes to the margins those deemed to be 'old', 'frail' or 'confused', or even excludes them altogether through the differentiation processes operating around consumer culture and its validation of active ageing.

\section{The discourse of brain training and how it enables the 'will to health'}

Whether people actually improve their cognitive health and prevent or delay the onset of dementia through the practices of brain training is outwith the concerns of this paper. Rather what is of importance is how such practices relate to dominant discourses of active ageing and the extent that they connect to an apparent 'will to health' (Higgs et al. 2009). The 'will to health' in later life can be associated with biological citizenship. Hence, it characterises the way in which individuals experience social pressures to act responsibly as managers of their own health, and to demonstrate this will in order to fit to certain social norms. According to Higgs et al. (2009), the 'will to health' has been elevated to become a normative expectation for all citizens with the transformations of western society taking place throughout the second half of the $20^{\text {th }}$ century. As such, the 'will to health' has become associated with policies of 'active ageing' (Higgs et al. 2009:693). They further argue that this change has reinforced the distinction between natural and normative ageing. What they describe as natural ageing results 
from 'cultural or ethical considerations about the length and purpose of human life' (2009:691). Increasingly normative ageing has become inculcated with 'norms of self-care aimed at delaying such decline' (Higgs et al. 2009:687) to the extent that the distinction between the third and fourth ages becomes very significant. In these circumstances the ideal of 'active ageing' is not only normative, it can be translated into social pressures on citizens to demonstrate certain standards of (cognitive) health in later life (Jaye et al. 2018; Latimer 2018). The use of brain training as a way of not only offsetting the possibility of cognitive decline but also of demonstrating an ethos of self-care becomes evident here. This ethos of self-care and the 'will to health' around dementia prevention may emerge from different sources. For instance, Lawless, Augoustinos and Lecouteur (2018) have showed how several associations active in the field of dementia have spread messages embracing this ethos and 'will to health' through their online platforms. Indeed, in their review of the websites of 8 non-profit dementia organizations listed by Alzheimer Disease International, Lawless, Augoustinos and Lecouteur (2018:1548) have argued that online information on dementia risk and prevention available to the public "works to construct participation in prevention as desirable, necessary, and obligatory, despite ongoing debate about the benefit of such practices". In many ways therefore, the brain training discourse comes to insert itself into a landscape of prescriptions presenting the most appropriate behaviour to adopt in the face of dementia through riskmanagement practices.

As stated earlier, neuroplasticity plays a key-role in this narrative as a mechanism through which individual action is supposed to act in order to achieve these outcomes. In analysing the 'will to health' in face of cognitive decline, Millington reminds us that this will is 'evidently both enabling and constraining' (2012:442). Drawing on Gilleard and Higgs (2010; 2014) again, we can see the reinforcement of the divide between third and fourth age, and the pressure that there is on older individuals to maintain elevated norms of cognitive capacity, or at least 
demonstrate that they are attempting to do so. Higgs et al. see the reinforcement of this distinction between natural and normal ageing as located in the development of 'technologies of the self' (2009:691). In Millington's (2012) own analysis of brain training devices, he describes the way in which brain training possesses such characteristics. The originator of this concept, Michel Foucault (1988: 18) describes 'technologies of the self' as being the ones that, by their use, could enable individuals to develop a set of 'operations on their own bodies and souls, thoughts, conduct, and way of being, so as to transform themselves in order to attain a certain state of happiness, purity, wisdom, perfection, or immortality'. Hence, we can reasonably state that the use of such technologies encourages forms of individual management of health-risk in the face of cognitive decline which could lead to frustration if the outcomes claimed by the providers of such technologies do not emerge. It is interesting to note that even given the seriousness of its therapeutic intent and the potential frustrations of it not achieving these ends brain training can coexist with the enjoyable nature of playing many of the games that are features of it. Wade (2018) proposes a relevant insight into this compatibility through his framing of it as 'virtuous play'. Indeed, from his study of the brain training industry he points out that 'consumerist imperatives under late capitalism necessitate that achieving virtuosity need not be a chore, but rather enjoyable means of self-care' (Wade 2018:302). Wade traces the cultural origin of this form of virtuous play within the "neoliberal aversions to the unproductive, neurodegenerative, and insufficiently 'well' subjects” (2018:313).

More broadly, Williams, Higgs and Katz have described how a 'neuroculture' encompassing brain training has come to integrate the values of active ageing as a '[consequence] for the role played by cognitive health and memory in determining the onset of the fourth age' (2012:65). This has led some authors to identify the emergence of what they describe as a 'hypercognitive society that expects infallible, anti-age-able cognitive skills affect[ing] cultural narratives about aging, mind, body, and personhood' (Katz and Peters 2008:349). The brain training industry is 
consequently only one part of this emerging social reality. However it is a manifestation of the way in which the third/ fourth age fracture reproduces if not actually stimulates this distinction. Individual brain training practices are relating to a technology whose design and marketing are imbricated in ideas about self-management and individual responsibility to health, so much so that we would argue that we can talk of the emergence of active cognitive ageing.

\section{Using distinction to understand practices of prevention in cognitive decline}

Thus far we have concentrated on outlining the relevance of the concepts of the third and fourth age to the ideas behind brain training. However, we now seek to go further and suggest that these concepts are articulated through the practices of distinction which we would argue are a hallmark of contemporary technologies of the self. Of necessity, this leads us to the work of Pierre Bourdieu. In part, some of this work has been undertaken by writers discussing the 'generational habitus' of the third age (Gilleard and Higgs 2005; Higgs and McGowan 2013). However while there has been an articulation of habitus drawing on Bourdieu's work much less attention has been given to issues of distinction (Tulle 2007). In much of the work on the generational habitus of the third age there is a recognition that many of the dispositions present there are as much about rejecting the negative connotations of old age as they are about social positioning within the older generation. Given that cognitive decline is seen as a feature of old age as much as frailty it is unsurprising that practices of distinction are aimed at both other participants in third age culture as well as those who can be deemed as 'old people' (Gilleard and Higgs 2011). The commercial success of anti-ageing treatments and techniques can be seen as a testament of this process of dual distinction (Twigg and Majima 2014). Inscribed in the habitus surrounding the third age is not only the rejection of cognitive decline but also a legitimation of the consumption of brain training products as a way of allowing ageing 
individuals to remain in the continuous stage of life that Sarah Harper called 'active adulthood' (Brown 2017).

Generational habitus directed towards an idealized 'ageless ageing' (Andrews 2000), however, is only one part of how brain training connects with the tensions created by the third and fourth age. There also needs to be a recognition of the value of understanding the role of distinction in both positioning older people and deepening the tensions that exist between these two different experiences of old age.

Extending themes that are present in Bourdieu's work on how education, social origin and cultural preferences allow individuals to position themselves in society (Bourdieu, 1979), we would contend that the emergence of specific forms of neurocultural practice allow for similar forms of positioning. In this process, a key line of demarcation is whether or not certain practices demonstrate a continued cognitive capacity which can counter intimations of decline. There has already been considerable work published showing how issues of distinction relate to physical health and of the way in which the body becomes a project on its own. (Cockerham, Rütten and Abel 1997; Collyer et al. 2015; Frew and McGillivray 2005; Higgs and Gilleard 2015; Korp 2008; Williams 1995) Notions of distinction have been identified in healthy ageing discourses as individuals seek to prove that they are actively resisting decline (Allain and Marshall 2017; Palmer, Tulle and Bowness 2018). It must also be noted that the distinction practices we are drawing attention to are not ones primarily of social class, rather they are about rejecting a 'discreditable' identity defined by cognitive decline and dependency. These practices are therefore about preventing individual older people finding themselves subsumed under the social imaginary of the fourth age. 


\section{Quantification of the body and neuroplasticity: bridging Bourdieu's theory of distinction and the distinction of embodiment}

The design of brain training software packages along with their reliance on the idea of neuroplasticity are constructed to enable cognitive distinction, for instance, through the inclusion of standardised metrics and their exchange on social media as we mentioned earlier. This facilitates the development of practices of distinction among users as well as against a template of norms (Katz and Marshall 2018). We would argue that it enables both comparison and social positioning. Furthermore, neuroplasticity offers the possibility for users to imagine that they can be active agents in facing cognitive decline and the threat of dementia. This connects to the ideal of the 'will to health' around this condition as we presented earlier. Comparison is an essential component of commercial brain training games. One marketed game establishes age-categories as significant units for comparison. The use of age categories may be artefactual but it might be a way of convincing individuals to see such training as being relevant across the entire lifespan and thereby constantly keeping them within a logic of selfevaluation and training in order to motivate an improvement of performance.

Linking with Bourdieu's concept of habitus, Paulson (2005) mentions the following: "Bourdieu (1984) also offered a convincing argument for combining the social constructionist and phenomenological discourses. He defined the body in terms of 'physical capital', a commodification of the body, and described the social values given to the sizes, shapes and appearances of bodies. His concept of 'habitus' referred to socially instilled bodily dispositions. Thus, an individual's bodily disposition is a direct reflection of their social class, and is portrayed by their embodied taste and style. Social stratification thus occurs through classification of the body: and cultural intermediaries are important in transmitting bodily dispositions." (Paulson 2005: 232) In the design of these products, whether they trigger processes of distinction among users or not, we can see that mechanisms enabling social 
differentiation are very much present through the construction of metrics and the ubiquity of comparison with others. We argue that these intrinsic characteristics promoting a more socially valorised self are inevitably bound up in the use of such technologies for the purposes of distinction. Comparison, and the inscription of the quantified self in the social is also an important aspect of the fitness trackers more generally, whether they aim at measuring body fitness, or brain fitness in this case. Brain training and its quantification of cognition therefore inscribes itself within the current expanding scientific debates around the impact of the 'quantified self' on subjectivity today. Scholars such as Deborah Lupton (2016; 2019), or Dawn Nafus and Gina Neff (2016) have substantially participated to this conversation by theorizing how the current intensification of data collection regarding the body transforms our position in the social world. Although more modestly some theorization of the 'quantified self' has also taken place within social studies of ageing and health (e.g.: Oxlund 2012; Andersen and Whyte 2014). This has been concerned with how people come to understand body functioning in the context of chronic illnesses or the experience of the ageing process. In regard to the social dimension of quantification specifically, Deborah Lupton (2016:108) speaks about 'communal self-tracking' as a way to describe such practices through the facilitation offered by online social networks. We can consequently see that there are multiple facets to brain training. On one hand, there is a strong emphasis on its nature as a technology of the self, as we have seen earlier, and on the other hand, there are integral aspects of the platforms that host brain training software packages aimed at reinforcing comparison with other consumers.

Being seen as similar to conventional measurements of intelligence such as IQ, these metrics represent more advanced and more easily disseminated forms of comparative measurement. Significantly, while IQ scores were measures that remained relatively static and were meant to be used for specific classificatory purposes, metrics within brain training come to directly involve the unattainable objective of fitness that Zygmunt Bauman (2000) associated with late 
capitalism (cf Higgs 2012). Individuals themselves apply forms of self-monitoring that are characteristic of subjectivities that are produced in our current societies of control as Deleuze (1992) presents them. In his presentation of current transformations of the relations of production in contemporary society, Deleuze (1992:5) explains how individuals are now expected to fulfil norms of perpetual training as part of the underlying rules of competition that expect individuals to constantly engage in comparison with each other. Such 'perpetual training' is a new form of disciplinary power he argues and reflects aspects of the "new medicine 'without doctor or patient' that singles out potential sick people and subjects at risk" (Deleuze 1992:7). Brain training is one of the myriad of examples that represents this shift. Neuroplasticity, as we saw earlier, is the component that allows such integration within a new realm of 'governmentality' of the self, enabling the brain to become a project on its own (Williams, Higgs and Katz 2011:67). Comparison with others offers constant opportunities to demonstrate the difference between the individual and the performances of others. It is dynamic in contrast to the externally applied and fixed attributions of quantifications such as IQ. It also engages with the cultures of contemporary consumerism by rendering neuroplasticity a popular matter that individuals can engage with through social media. In much the same way that the gym has opened up issues of physical distinction, brain training has created the possibilities for such distinction in the cognitive realm. Significantly while such 'technologies of distinction' can operate across the whole lifespan, it is at older ages that it has most salience.

\section{Understanding the impact of distinction on the imaginary of ageing}

Technologies such a brain training situate individuals in a hierarchy by reifying scales of cognitive abilities through the operation of metrics. Such technologies enable individuals to demonstrate a 'will to health' (Millington 2012; Ziguras 2004) which valorises culturally 
valued health practices. While the 'will to health' enables practices of differentiation within an agentic society, in the field of ageing, however, it also creates a platform for excluding those who are seemingly unable to demonstrate 'a will to health'. This bifurcation emerges from the divide between the practices of the third age and the social imaginary of the fourth age. Peter Laslett (1989) in his celebrated A new map of life not only discussed the promise of the third age but drew attention to the decrepitude and death associated with its opposite - the fourth age. This feared old age is the core of Gilleard and Higgs conceptualisation of it as 'ageing without agency'; an existence that those in the third age keep their distance from. As Gilleard and Higgs (2010:122) point out the fourth age is 'an inevitable end that could at best be marginalized to the edges of life'.

The fourth age represents the most negative aspects of ageing and is reinforced when it is instrumentalized to trigger anxiety. The video 'share the orange', promoted by Alzheimer Research UK (2018), and shared over 2 million times at the time of writing this article is a good illustration of the use of the ontological intensity surrounding the fear of dementia projected by the fourth age. In this video, the memory of a lifetime is represented through engraved symbols on the peel of an orange on which two small characters wander through the stages of life, the orange symbolizing the brain. Chronologically in the video, we follow the stereotypical love story between these two characters, retracing the meaningful events of a lifetime, from their first romance, to the wedding and birth of children, and so forth, until they progress into old age. Life runs smoothly until we hit the dramatic milestone of the narrative. The man sitting peacefully on a chair with his spouse becomes subjugated by panic as he realizes that she is slowly vanishing away in front of his gaze. The same happens to his children who also vanish as do all the memories of a life that had been engraved on the surface of the orange. The man wanders around in confusion on the surface of the orange until the peel itself 
disappears. The segments of the orange then become apparent, after disappearing one by one as well.

Alzheimer's disease in this distressing narrative is not simply a condition, but the disappearance of a life into an abyss. The orange, used as a representation of the declining brain, has lost its peel, and all its pieces at the end of the narrative, except for the remaining segment. The objective of the video is ultimately to argue that Alzheimer is not a normal part of ageing but rather 'a physical disease that we can fight'. What we draw from it therefore is that dominant narratives of dementia and the anxiety that they provoke are ultimately of an existential nature, associated with the prospect of the disappearance of the mind. With this in mind we can argue that distinction in later life takes on a more existential character; a distinction that is not generally present in the studies of hierarchies of class and/or social identities. Focusing on enhancing cognitive performance is different from many other forms of distinction because not only does it allow for a differentiation with others, it also allows for a distancing of individuals from dementia. By training the brain in later life, individuals are in effect engaging with the ontological threat of dementia. 'Choosing' to be 'inactive' in relation to cognitive health in later life may therefore represent a form of acceptance of the premature and distressing disappearance of the brain and the mind portrayed in the 'share the orange' narrative. Such an anxiety, and the distinctions that follow from it are important components of the 'event horizon' that exists between Andrews 'ageless ageing' associated with the third age and the dependency and abjection of the 'ageing without agency' of the fourth age.

It is also important to note that this fear of decline is not confined to cognitive function. Attempts by individuals to maintain certain level of physical performance in later life are very much associated with a fear of losing capacities. Dionigi, Horton and Baker (2013) point out how important it is for master athletes to maintain their performance and ability to compete by continuing to train their bodies. Significantly they show that 'the individual and cultural fear 
of decline in old age (...) can act as key motivating factors for performance preservation in later life' (Ibid. 317), in which ageing well, and the idea of 'use it, or lose it' become powerful obligations (Ibid. 316). This is not just confined to those in late middle age as Nosraty et al. (2015) point out in their study of community dwelling Finns aged over 90. Furthermore, Whyte and Andersen describe how metrics of the body can become a source of anxiety by rendering the body's functioning and deficiencies graspable by individuals in conditions such as diabetes (2014:266). Metrics of cognition in later life and the idea that brain capacity can be quantified in the same way as heartbeat, cholesterol or blood pressure can all be taken to create a generalised strategy of distinction aimed at keeping the fourth age at bay. In a way, it creates a new sense of 'normative' ageing which is as much aspirational as it is 'normal' (Jones and Higgs 2010).

In the context of distinction, brain training therefore comes to insert itself as a technology of distinction which exploits existing processes of differentiation relating to the intensification of the active cognitive ageing discourse. Indeed, by its use, it enables individuals to present themselves as active and responsible 'third agers', utilising socially validated techniques to keep dementia at distance, and more importantly avoiding association with the fourth age imaginary of 'failed' ageing.

\section{The impact of practices of distinction on people with dementia}

In addition to creating systems of social and cultural differentiation, distinction can also be a process of 'othering' (Schwalbe, 2000) with the marginalisation of people living with dementia being an unintended casualty thrown up by the third/fourth age divide (Higgs and Gilleard 2014). Indeed, 'othering' for Gilleard and Higgs (2015:264) 'is essentially a catch-all term to describe the attributions made by other people of persons who seem powerless to assert their 
own identity or realise their social agency', in this case being the persons with dementia. Supporting this position, it is important to underline a point mentioned by Featherstone (1990), that Bourdieu (1984) already developed ways of understanding how consumption choices and lifestyle preferences not only involved discriminatory judgements but also created ways of transmitting those classifications to others. As Featherstone (1990:11) wrote: 'particular constellations of taste, consumption practices and lifestyles practices are associated with particular occupations and class fractions, making it possible to map out the universe of taste and lifestyles with its structured oppositions and finely graded distinctions which operate within a particular society at a particular point in history'. Hence, following this point applied to later life and questions of health and ageing, it is therefore possible to envision how forms of 'discriminatory judgement' come to delineate the cultural coordinates of the third Age, while also classifying people with dementia as 'others', externally inscribing them as enveloped by the fourth Age.

Although there has been widespread acknowledgement of the social differentiation and social re-positioning that occurs for people with diagnosed or perceived cognitive impairment (Beard 2004; 2016; Beard and Fox 2008; Tolhurst and Kingston 2013), we argue that this external attribution of otherness based on the promotion of active ageing; one based on the idea of distinction, has not been fully considered as yet. Indeed, previous attempts to look at social differentiation around dementia have led to a concerted effort to address what has been described by Tom Kitwood (1997) as the 'malignant social psychology' that negatively affects people with dementia. This has been a stimulus not only for person-centred care but also for ideas of personhood which go beyond an essentialisation of cognitive capacity. This work remains highly influential (Bartlett, 2016; Bartlett and O'Connor 2010) in redefining society's relationship to the person with dementia and their capacities and potential agency. Addressing the nature of social relationships is seen to change the capacity of the person with dementia by 
cancelling the effect of disabling relations of care by restoring their personhood. Taking their cue from Kitwood, more recent interventions have re-articulated the concept of citizenship in order to 'interpret inclusive and exclusive practices which potentially create opportunity for participation or reinforce the loss of citizenship for older people with dementia.' (Brannelly 2011:662). Such a view contends that the othering of dementia can be ameliorated through the transformation of society's perception of dementia. The use of language has therefore been an important strategy in order to change society's view of dementia. Replacing expressions such as 'being demented' with 'having dementia', or 'demented people' with 'people with dementia' have been among the most salient examples undertaken by groups such as the Dementia Engagement and Empowerment Project, ${ }^{\mathrm{ii}}$ and Dementia Australia, ${ }^{\mathrm{iii}}$ or by dementia researchers (e.g. Sabat et al. 2011). While not intending to undermine the importance of such initiatives for advancing the position of people with dementia within society, we also think that this approach fails to engage with the intrinsic cultural processes that 'other' people living with dementia today.

Challenging the primacy of accounts that could be subsumed under the rubric of stigma a whole other set of cultural dynamics are ignored. Given that most accounts of stigma are located within interactional approaches to social action and rarely address more structural issues (Scambler 2009) there are difficulties in disentangling what seem to be 'unfair' attributions from social processes. Hence the focus on de-stigmatisation and education. We argue that the sources of stigma in this area are deeply rooted within cultural perceptions of old age and its existential fears. Concerns with decline and the loss of agency that accompany old age are commonplace in all cultures. In contemporary society, the avoidance of the degradations associated with illness and ageing have been described as a 'decline ideology' (Gullette 2017) but it motivates a desire to steer clear of intimations of cognitive impairment and dementia. Considerable effort is therefore put into prevention practices as well as the encouragement of 
all people to participate and support research on dementia. It is not likely that the majority will 'embrace' the condition and treat it as a difference in the way that is common within the disability movement. For many older people it is only through individual risk management of the practices and discourses of active ageing that they can approach this age associated condition. Consequently while many advocacy organisations want to de-stigmatise the condition they are also involved in setting up discourses that can facilitate the divisions they wish to overcome (e.g. Alzheimer's Society website, ${ }^{\text {iv }}$ Lawless, Augoustinos and Lecouteur 2018). In this way it could be argued, the malignant social psychology that affects people with dementia is not only a question of the lack of an attribution of personhood, but could also be a result of the prevention practices such as brain training which aim to distance people from dementia.

\section{Conclusion}

In this paper, we have argued that the gerontological social sciences have not fully considered the significance of the idea of distinction for understanding the role of technologies such as brain training in later life. We believe that it is important to study such practices of distinction if we are to understand more fully the differentiations that are now part and parcel of contemporary later life. We therefore wish to enrich the current literature on ageing, dementia and technology where analyses covering social exclusion within later life remain absent or limited to various elaborations of the developing digital divide resulting from inequalities issues of access to and usability of technologies. It could be argued that such outcomes are the product of an overarching ageism which pitches society against older people, however we would argue that such perspectives overstate the totalising capacity of the concept and underplay the social and corporeal dimensions bound up with experiences of ageing (See Higgs 
and Gilleard 2019). More nuanced approaches such as those that see the importance of the role of the social imaginaries of the fourth age in situating the practices of distinction help extend our understanding of the contradictory processes of contemporary ageing. As in other areas where processes of distinction are used as forms of social power, being aware of the cultural demarcations between the third and fourth ages helps identify the production of these new forms of social exclusion occurring in old age. We contend that the emergence of commercial ventures promoting brain training alongside the kind of rhetoric that is used to advertise such products provides a good example of such distinction practices. Such endeavours also conform to the reconfiguration of ageing and the promotion of the 'fit mind and body' that proliferates within contemporary societies. Neuroplasticity - the idea that people can maintain cognition through regular exercises - and the various scales and metrics reifying the quantification of brain performance as well as its comparison have played a crucial role within the development of such technologies as well as their conformity to Zygmunt Bauman's notion of the objective of fitness. With brain training explicitly drawing on the analogy of training the body, the idea of cognition as a modifiable object that can be developed has facilitated a more specific form of active ageing to one that could be described as active cognitive ageing.

It is this active cognitive ageing, we would argue, that allows brain training to become an important means of social positioning. This form of social positioning, however, is not directly related to class position or cultural identity. Rather it is a positioning away from the negative social imaginary of the fourth age, which when associated with decline and dependency comes to represent the most undesired sides of old age within Western society. To understand this social positioning, we adapted Bourdieu's concept of distinction wherein consumption choices made by people enable them to position themselves within a social class habitus, and distance themselves from other social classes. Taking this model, we argue that as people progress into later life they are continually called to engage with the ideal of active ageing. Engaging with 
brain training products allows older people to position themselves away from dementia and thereby the fourth age. It allows them to demonstrate to themselves and others their cognitive health. Following the late Foucault, such 'technologies of the self' become markers of social virtue rather than being function acts or even leisure activities.

It is our argument that such technologies, promoted without clear evidence of efficacy and relying upon images of dementia as a social and positional failure, constitute what we have called technologies of distinction. This differentiation is double-edged: further relegating and stigmatizing those individuals with cognitive limitations who are rendered the 'other' to these discourses of successful distinction. Distinction, and the intensifying possibility of its extension into the domain of cognition, may become an important factor reinforcing the social divisions of later life between the able body/brain, and the impaired one. While much attention has been focused on the causation of inequalities in later life, less attention has been given to the impact within old age of corporeal divisions of which dementia alongside frailty may be an important one (Gilleard and Higgs 2017). Moreover, given the lack of efficacy of brain training to prevent decline little attention has been paid to what happens to those whose use of the technology starts to record the decline it is trying to prevent. A whole host of both individual and ethical issues emerge.

This paper has primarily focused on the processes of distinction apparent in brain training and has pointed to the role that they may play in differentiating older people within the cultural field of the third age and positioning them in relation to the social imaginaries of the fourth age. At the same time it also wishes to point out that the whole field of ageing is going to be increasingly enmeshed in the contradictions and tensions that are brought about by such technological developments and the challenges of how humans interface with them. In contemporary ageing, the role of technological development is likely to be a key terrain which older people will have to navigate in order to live their lives. The ideal of active ageing is now, 
through the emphasis of 'use it or lose it', potentially expanding active cognitive ageing with all its corresponding normative assumptions to larger sections of the older population. Older people may find that whether such techniques work or not becomes secondary to the societal expectation that all older people should engage in as full a range of health promoting activities as possible if they are not to fall into the category of the dependent 'other'. In this way we would argue the technologies of distinction come to play a key role in reordering old age in modern society and this is something that researchers in ageing as well as others should not only become aware of , but should also direct their attention to studying. 


\section{References:}

Allain KA and Marshall B (2017) Foucault retires to the gym: Understanding embodied aging in the third age. Canadian Journal on Aging/La Revue canadienne du vieillissement 36, 402-14.

Alzheimer's Research UK website (2018) Share the orange. Available online at https://www.alzheimersresearchuk.org/orange/

Alzheimer's Society website (n.d.) How to reduce your risk of dementia. Available online at https://www.alzheimers.org.uk/about-dementia/risk-factors-and-prevention/how-reduce-your-riskdementia

Andersen J and Whyte S (2014) Measuring risk, managing values: Health technology and subjectivity in Denmark. Anthropology \& Medicine 21, 265-76.

Andrews M (2000) Ageful and proud. Ageing \& Society 20, 791-5.

Bahar-Fuchs A, Clare L and Woods B (2013) Cognitive training and cognitive rehabilitation for mild to moderate Alzheimer's disease and vascular dementia. Cochrane Database of Systematic Reviews $\mathbf{6}$, CD003260.

Baltes PB and Smith J (2003) New frontiers in the future of aging: From successful aging of the young old to the dilemmas of the fourth age. Gerontology 49, 123-35.

Bartlett R (2016) Scanning the conceptual horizons of citizenship. Dementia 15, 453-61.

Bartlett R and O'Connor D (2010) Broadening the dementia debate: Towards social citizenship. Policy press, Bristol.

Bauman Z (2000) Liquid Modernity. Cambridge: Polity Press.

Beard RL (2004) In their voices: Identity preservation and experiences of Alzheimer's disease. Journal of Aging Studies 18, 415-28.

Beard RL (2016) Living with Alzheimer's: Managing memory loss, identity, and illness. NYU Press. 
Beard RL and Fox PJ (2008) Resisting social disenfranchisement: Negotiating collective identities and everyday life with memory loss. Social science \& medicine 66, 1509-20.

Bourdieu P (1979) La distinction : Critique sociale du jugement. Paris: Éditions de Minuit.

Bourdieu P (1984) Distinction: A Social Critique of the Judgement of Taste. London: Routledge.

Brannelly T (2011) Sustaining citizenship: People with dementia and the phenomenon of social death. Nursing Ethics 18, 662-71.

Brown M (2017) Don't call people 'old' until death is near, says gerontologist. The Guardian, May 30. Available online at https://www.theguardian.com/science/2017/may/30/old-people-death-70s-80sactive-adults

Calasanti T and King N (2011) A feminist lens on the third age: Refining the framework. in D Carr and K Komp (eds) Gerontology in the era of the third age, Springer, New York 67-85.

Cockerham WC, Rütten A and Abel T (1997) Conceptualizing contemporary health lifestyles: moving beyond Weber. Sociological Quarterly 38, 321-42.

Collyer FM, Willis KF, Franklin M, Harley K and Short SD (2015) Healthcare choice: Bourdieu's capital, habitus and field. Current Sociology 63, 685-99.

Corbett A, Owen A, Hampshire A, Grahn J, Stenton R, Dajani S, Burns A, Howard R, Williams N, Williams G and Ballard C (2015) The Effect of an Online Cognitive Training Package in Healthy Older Adults: An Online Randomized Controlled Trial. Journal of the American Medical Directors Association 16, 990-7.

Dakim Website (n.d.) It Matters to Your Residents. Available online at https://www.dakim.com/dakim-slp/\#why

Darzi L (2014) Dementia report: 'Use it or lose it' to protect against disease. The Telegraph, December 22. Available online at https://www.telegraph.co.uk/news/health/news/11295345/Dementia-reportUse-it-or-lose-it-to-protect-against-disease.html 
Deleuze G (1992) Postscript on the Societies of Control. October 59, 3-7. Available online at http://www.jstor.org/stable/778828

Delvecchio Good M, Good B, Schaffer C and Lind S (1990) American oncology and the discourse on hope. Culture, Medicine and Psychiatry 14, 1, 59-79.

Delvecchio Good M (2010) The Medical Imaginary and the Biotechnical Embrace: Subjective Experiences of Clinical Scientists and Patients. In Good BJ, Fischer MMJ, Willen SS and Delvecchio Good M (eds), A Reader in Medical Anthropology: Theoretical Trajectories, Emergent Realities. Chichester: Wiley-Blackwell, pp. 272-283.

Dementia Australia Website (n.d.) Dementia Language Guidelines. Available online at https://www.dementia.org.au/resources/dementia-language-guidelines

Dementia Engagement and Empowerment Project (2014) Dementia words matter: Guidelines on language about dementia. Available online at http://dementiavoices.org.uk/2014/10/dementia-words$\underline{\text { matter/ }}$

Devlin K (2009) Millions asked to take part in the first mass test of 'brain training'. The Telegraph, September 7. Available online at https://www.telegraph.co.uk/news/health/news/6140544/Millionsasked-to-take-part-in-the-first-mass-test-of-brain-training.html

Dionigi R, Horton S and Baker J (2013) How do Older Masters Athletes Account for their Performance Preservation? A Qualitative Analysis. Ageing and Society 33, 297-319.

Featherstone M (1990) Perspectives on Consumer Culture. Sociology 24, 5-22.

Federal Trade Commission Website (2016) Lumosity to Pay \$2 Million to Settle FTC Deceptive Advertising Charges for Its "Brain Training" Program, January 5. Available online at https://www.ftc.gov/news-events/press-releases/2016/01/lumosity-pay-2-million-settle-ftc-deceptiveadvertising-charges

Foucault M (1982) Technologies of the self. In P Hutton, L Martin and H Gutman (1988), Technologies of the self: A seminar with Michel Foucault. (pp. 16-49). London: Tavistock. 
Fratiglioni L, Paillard-Borg S and Winblad B (2004) An active and socially integrated lifestyle in late life might protect against dementia. The Lancet Neurology 3, 343-53.

Frew M and McGillivray D (2005) Health clubs and body politics: Aesthetics and the quest for physical capital. Leisure studies 24, 161-75.

George DR and Whitehouse PJ (2011) Marketplace of Memory: What the Brain Fitness Technology Industry Says about Us and How We Can Do Better. The Gerontologist 51, 590-6.

Gilleard C and Higgs P (2005) Contexts of Ageing Class, Cohort and Community. Cambridge: Polity.

Gilleard C and Higgs P (2010) Aging without agency: Theorizing the fourth age, Aging \& Mental Health 14, 121-128.

Gilleard C and Higgs P (2011) 'The third age as a cultural field', in D Carr and K Komp (eds), Gerontology in the Era of the Third Age (pp. 33-50), New York: Springer.

Gilleard C and Higgs P (2014) Studying dementia: the relevance of the fourth age. Quality in Ageing and Older Adults 15, 241-3.

Gilleard C and Higgs P (2015) Social death and the moral identity of the fourth age, Contemporary Social Science 10, 262-271.

Gilleard C and Higgs P (2017) Ageing, corporeality and social divisions in later life. Ageing \& Society 37, 1681-702.

Gullette MM (2017) Ending Ageism, or How Not to Shoot Old People. Rutgers University Press.

Hazan H (2011) Gerontological autism: terms of accountability in the cultural study of the category of the Fourth Age. Ageing \& Society 31, 1125-40.

Higgs, P (2012) Consuming bodies: Zygmunt Bauman on the difference between fitness and health. In G Scambler (ed) Contemporary Theorists for Medical Sociology Routledge, London (30-42).

Higgs P and Gilleard C (2014) Frailty, abjection and the 'othering' of the fourth age. Health Sociology Review 23, 10-9. 
Higgs P and Gilleard C (2015) Fitness and Consumerism in Later Life. In E Tulle and C Phoenix (Eds.). Physical activity and sport in later life: Critical perspectives. Palgrave Macmillan, London, $32-47$.

Higgs P and Gilleard C (2019) The ideology of ageism versus the social imaginary of the fourth age: two differing approaches to the negative contexts of old age. Ageing \& Society, 1-14. doi:10.1017/S0144686X19000096

Higgs P, Leontowitsch M, Stevenson F and Jones IR (2009) Not just old and sick - the 'will to health' in later life. Ageing \& Society 29, 687-707.

Higgs P and McGowan F (2013) 'Aging, embodiment and the Third and Fourth Ages', in A Kampf, B L Marshall and A Petersen (eds), Aging Men, Masculinities and Modern Medicine (pp. 21-34), Oxon: Routledge.

Jaye C, Young J, Egan R, Llewellyn R, Cunningham W and Radue P (2018) The healthy lifestyle in longevity narratives. Social Theory \& Health 16, 361-78

Jones IR and Higgs PF (2010) The natural, the normal and the normative: Contested terrains in ageing and old age. Social science \& medicine 71, 1513-9.

Katz S and Marshall BL (2018) Tracked and fit: FitBits, brain games, and the quantified aging body. Journal of aging studies $\mathbf{4 5}, 63-8$.

Katz S and Peters K (2008) Enhancing the mind? Memory medicine, dementia, and the aging brain. Journal of Aging Studies 22, 348-55.

Kitwood T (1997) Dementia reconsidered: The person comes first. Buckingham: Open University Press.

Korp P (2008) The symbolic power of 'healthy lifestyles'. Health sociology review 17, 18-26.

Laslett P (1989) A fresh map of life. London: Weidenfeld and Nicholson. 
Latimer J (2018) Repelling neoliberal world-making? How the ageing-dementia relation is reassembling the social. The Sociological Review 66, 832-56.

Lawless M, Augoustinos M and Lecouteur A (2018) "Your Brain Matters": Issues of Risk and Responsibility in Online Dementia Prevention Information. Qualitative Health Research 28, 1539-51.

Livingston G, Sommerlad A, Orgeta V, Costafreda SG, Huntley J, Ames D, Ballard C, Banerjee S, Burns A, Cohen-Mansfield J, Cooper C, Fox N, Gitlin L, Howard R, Kales H, Larson E, Ritchie K, Rockwood K, Sampson E, Samus Q, Schneider L, Selbaek G, Teri L and Mukadam N (2017) Dementia prevention, intervention, and care. The Lancet 390, 2673-34.

Lloyd L, Calnan M, Cameron A, Seymour J and Smith R (2014) Identity in the fourth age: perseverance, adaptation and maintaining dignity. Ageing \& Society 34, 1-19.

Lumosity Website (n.d.). Homepage. Available online at https://www.lumosity.com/ Lupton D (2016) The quantified self: A sociology of self-tracking. Cambridge: Polity Press. Lupton, D (2019) The thing-power of the human-app health assemblage: thinking with vital materialism. Social Theory and Health 17, 125-39. https://doi.org/10.1057/s41285-019-00096-y Merrild CH, Andersen RS, Risør MB and Vedsted P (2017) Resisting "reason”: A comparative anthropological study of social differences and resistance toward health promotion and illness prevention in Denmark. Medical anthropology quarterly 31, 218-36.

Millington B (2012) Use it or lose it: Ageing and the politics of brain training. Leisure Studies 31, $429-46$.

Nafus D and Neff G (2016) Self-tracking. Cambridge, Massachusetts: The MIT Press.

Nosraty L, Jylhä M, Raittila T and Lumme-Sandt K (2015) Perceptions by the oldest old of successful aging, Vitality 90+ Study. Journal of aging studies 32, 50-8.

Owen AM, Hampshire A, Grahn JA, Stenton R, Dajani S, Burns AS, Howard RJ and Ballard CG (2010) Putting brain training to the test. Nature 465, 775-8. 
Oxlund B (2012) Living by numbers: the dynamic interplay of asymptomatic conditions and low-cost measurement technologies in the cases of two women in the Danish provinces. Soumen Antropologi: Journal of the Finnish Anthropological Society 37, 42-56.

Palmer VJ, Tulle E and Bowness J (2018) Physical Activity and the Ageing Body. In: SR Nyman, A Barker, T Haines, K Horton, C Musselwhite, G Peeters, CR Victor and JK Wolff (eds) The Palgrave Handbook of Ageing and Physical Activity Promotion (pp. 531-49). Palgrave Macmillan: Cham.

Paulson, S. (2005). How various 'cultures of fitness' shape subjective experiences of growing older. Ageing \& Society 25, 229-244.

Phoenix C and Smith B (2011) Telling a (good?) counter-story of aging: Natural bodybuilding meets the narrative of decline. Journals of Gerontology Series B: Psychological Sciences and Social Sciences 66, 628-39.

Pitts-Taylor V (2010) The plastic brain: Neoliberalism and the neuronal self. Health 14, 6, 635-52.

Public Health England (2018) Dementia: applying All Our Health. Available online at https://www.gov.uk/government/publications/dementia-applying-all-our-health/dementia-applyingall-our-health

Rose N and Abi-Rached JM (2013) Neuro: The new brain sciences and the management of the mind. Princeton; Oxford: Princeton University Press.

Rose N and Novas C (2005) Biological Citizenship. In A Ong and SJ Collier (eds), Global Assemblages: Technology, Politics, and Ethics as Anthropological Problems. (pp. 439-63). Malden, MA: Blackwell.

Sabat S, Johnson, A, Swarbrick C, and Keady J (2011) The 'demented other' or simply 'a person'? Extending the philosophical discourse of Naue and Kroll through the situated self. Nursing Philosophy 12, 282-92.

Scambler G (2009) Health-related stigma. Sociology of health \& illness 31, 441-55. 
Schwalbe M (2000) The elements of inequality. Contemporary Sociology 29, 775-81.

SharpBrains (2013) Web-based, mobile and biometrics-based technology to assess, monitor and enhance cognition and brain functioning: The digital brain health market, 2012-2020. San Francisco, CA: SharpBrains.

Simons D, Boot W, Charness N, Gathercole S, Chabris CF, Hambrick DZ and Stine-Morrow EAL (2016) Do “Brain-Training” Programs Work? Psychological Science in the Public Interest 17, 103 86.

The PROTECT Study Website (n.d.) Home. Available online at http://www.protectstudy.org.uk/default.aspx

Tolhurst E and Kingston P (2013) Understanding the experience of dementia: Utilising the theoretical insights of 'status passage'. Social Theory \& Health 11, 175-93.

Tulle E (2007) Running to run: Embodiment, structure and agency amongst veteran elite runners. Sociology 41, 329-46.

Twigg J and Majima S (2014) Consumption and the constitution of age: Expenditure patterns on clothing, hair and cosmetics among post-war 'baby boomers'. Journal of Aging Studies 30, 23-32.

Wade M (2018) Virtuous Play: The Ethics, Pleasures, and Burdens of Brain Training. Science as Culture 27, 296-321.

Williams SJ (1995) Theorising class, health and lifestyles: can Bourdieu help us? Sociology of health \& illness 17, 577-604.

Williams SJ, Higgs P and Katz S (2012) Neuroculture, active ageing and the 'older brain': problems, promises and prospects. Sociology of Health \& Illness 34, 64-78.

Ziguras C (2004) Self-Care: Embodiment, Personal Autonomy and the Shaping of Health Consciousness. Routledge, London 


\footnotetext{
${ }^{\mathrm{i}}$ To this regard, see Federal Trade Commission Website (2016) Lumosity to Pay \$2 Million to Settle FTC Deceptive Advertising Charges for Its "Brain Training" Program, January 5. Available online at https://www.ftc.gov/news-events/press-releases/2016/01/lumosity-pay-2-million-settle-ftc-deceptiveadvertising-charges

ii Dementia Engagement and Empowerment Project (2014) Dementia words matter: Guidelines on language about dementia. Available online at http://dementiavoices.org.uk/2014/10/dementia-words-matter/

iii Dementia Australia Website (n.d.) Dementia Language Guidelines. Available online at https://www.dementia.org.au/resources/dementia-language-guidelines

iv Alzheimer's Society website (n.d.) How to reduce your risk of dementia. Available online at https://www.alzheimers.org.uk/about-dementia/risk-factors-and-prevention/how-reduce-your-risk-dementia
} 